\title{
Multilocus genotype analysis outlines distinct histories for Trichinella britovi in the neighboring Mediterranean islands of Corsica and Sardinia
}

Giuseppe La Rosa ${ }^{1}$, Isabelle Vallée ${ }^{2}$, Gianluca Marucci ${ }^{2}$, François Casabianca ${ }^{3}$, Ennio Bandino ${ }^{4}$, Fabio Galati ${ }^{1}$, Pascal Boireau ${ }^{2}$ and Edoardo Pozio ${ }^{1 *}$

\begin{abstract}
Background: The zoonotic nematode Trichinella britovi was discovered in two neighboring Mediterranean islands of Corsica and Sardinia, almost simultaneously at the beginning of the 21st century. An epidemiological link between the two parasite populations was generally assumed. In 2015, an outbreak of trichinellosis in Nice, the South of France, was reportedly caused by the consumption of raw pork delicatessen imported from Corsica. The aims of the present study were to investigate, by multilocus genotype (MLG) analyses, the hypothesis of the common origin of the Corsican and Sardinian T. britovi foci and to trace "from fork to farm" the origin of the pork product, which caused a trichinellosis outbreak in mainland France in 2015.
\end{abstract}

Methods: Sixty-three T. britovi isolates were collected from animals and pork products of Sardinia and Corsica islands and from mainland of Italy, France and Spain. We analyzed genetic variability at four polymorphic microsatellite loci by two independent algorithms, the Bayesian and multivariate analyses, to evaluate the genetic relationships of 1367 single larvae.

Results: Trichinella britovi isolates of the two islands showed different genetic structures and the Bayesian analysis revealed a different membership of the two insular populations. Furthermore, two geographically separate genetic groups were identified among Corsican isolates. Lastly, the origin of the pork delicatessen marketed in Nice was linked to a breeder-butcher in Corsica.

Conclusions: The low level of genetic admixture of the insular T. britovi isolates suggests that this pathogen colonized the two islands by separate events. On the other hand in Corsica, although the isolates share the same genetic structure, geographically separate isolates showed different membership. We suggest the MLG analysis as a suitable method in supporting epidemiological investigations to trace "from fork to farm" insular populations of T. britovi.

Keywords: Trichinella britovi, Molecular epidemiology, Mediterranean islands, Pig, Wild boar, Fox, Trichinellosis, Microsatellite, Pork products

\footnotetext{
* Correspondence: edoardo.pozio@iss.it

${ }^{1}$ European Union Reference Laboratory for Parasites, Istituto Superiore di

Sanità, Rome, Italy

Full list of author information is available at the end of the article
}

(c) The Author(s). 2018 Open Access This article is distributed under the terms of the Creative Commons Attribution 4.0 International License (http://creativecommons.org/licenses/by/4.0/), which permits unrestricted use, distribution, and reproduction in any medium, provided you give appropriate credit to the original author(s) and the source, provide a link to the Creative Commons license, and indicate if changes were made. The Creative Commons Public Domain Dedication waiver (http://creativecommons.org/publicdomain/zero/1.0/) applies to the data made available in this article, unless otherwise stated. 


\section{Background}

Parasites of the genus Trichinella are zoonotic nematodes circulating among wild carnivore and omnivore animals with a cosmopolitan distribution on all continents except Antarctica [1]. When humans fail to properly manage domestic pigs and wildlife, Trichinella spp. are transmitted from the sylvatic to the domestic environment, triggering the onset of the domestic cycle [2]. Farming practices at risk of Trichinella spp. transmission occur, in general, in disadvantaged and poor areas due to several reasons including the lack of veterinary services, difficulties in controlling the myriad of small pig units, the rearing of pigs in backyards as well as the practice of allowing pigs to roam freely in the wild without any feed control [2].

Except for Sicily, where Trichinella spiralis was documented in pigs and humans from 1933 to 1961 [3], Trichinella spp. have never been recorded from the islands of the Mediterranean Basin until 2004, when Trichinella britovi was detected in free-ranging pigs in a remote mountainous area of Corsica [4]. One year later, a human outbreak of trichinellosis occurred in neighboring Sardinia following the consumption of pork from a free-ranging pig reared in a remote area of the island [5]. In the following years, extensive surveys showed that $T$. britovi was circulating among free-ranging pigs and wildlife of the two islands and an epidemiological link between the Corsican and Sardinian parasite populations was suspected due the almost simultaneous detection of the parasites on both islands, their geographical proximity, and the illegal animal trade between the two regions [6-8]. In 2015, an outbreak of trichinellosis occurred in the region of Nice, the South of France, due to the consumption of raw sausages imported from Corsica [9].

The Bayesian and multidimensional analyses of multilocus genotype data may constitute a useful tool to study the genetic structure of Trichinella populations originating from different continents and from restricted areas [10-12].

The aims of the present study were to investigate, by multilocus genotype analyses, the hypothesis of the common origin of the Corsican and Sardinian T. britovi foci and to trace "from fork to farm" the origin of the pork product, which caused a trichinellosis outbreak in mainland France in 2015. The results reject the hypothesis that $T$. britovi shares a common history in Corsica and Sardinia, and trace back the pork origin of the trichinellosis outbreak of Nice to a Corsican village.

\section{Methods}

\section{Investigated areas}

Corsica (France) with a surface area of $8680 \mathrm{~km}^{2}$ is the most mountainous island in the Mediterranean Sea. Mountains make up two-thirds of the island rising 2700 $m$ in height with deep and steep valleys. Almost $20 \%$ of the island is forest, and $3500 \mathrm{~km}^{2}$ of the territory is preserved as a nature reserve. The human population density of 37 inhabitants per $\mathrm{km}^{2}$ is about $1 / 3$ that of continental France.

Sardinia (Italy) is the second-largest island in the Mediterranean Sea, with an area of $24,100 \mathrm{~km}^{2}$. A sea loch of only $11 \mathrm{~km}$ separates this island from Corsica. Mountains cover about $13.6 \%$, hills about $67.9 \%$ and plains about $18.5 \%$ of the surface. The human population density of 69 inhabitants per $\mathrm{km}^{2}$ is about $1 / 3$ that of continental Italy.

\section{Trichinella spp. isolates}

In the present work, we conceive the terms: (i) "individual larva" or just "larva" as a single nematode organism of the genus Trichinella collected from striated muscles of naturally infected animals or meat products by artificial digestion; (ii) "isolate" as a group of larvae collected from striated muscles of naturally infected animals or meat products, by artificial digestion; and (iii) "population" as the T. britovi isolates present in each of five investigated areas, namely the Mediterranean islands of Corsica and Sardinia, and continental Italy, France and Spain (see below).

Trichinella britovi larvae were collected by artificial digestion according to the European Commission's regulations $[13,14]$ from animals originating from the only known focus in Sardinia (Orgosolo, 13 isolates) and from four foci in Corsica (Cozzano, Vallée de Gravona, Aullène and Bastelica; 17 isolates) as well as from raw pork delicatessen, 1 figatelli produced in Aullène (Corsica) and marketed in the Nice area (continental France) and 1 sausage collected from the breeder-butcher of Aullène, where figatelli had been produced (Table 1, Fig. 1). For the comparison of the genetic structure of $T$. britovi populations of the two islands with those of continental Europe, T. britovi larvae were collected from animals from continental Italy (9 isolates), continental France (14 isolates) and continental Spain (8 isolates) (Table 1, Fig. 1). Single larvae were washed 4 times with distilled water on ice and stored in $5 \mu \mathrm{l}$ of $90 \%$ ethyl alcohol at $-20{ }^{\circ} \mathrm{C}$.

Since four species of Trichinella occur in Europe and may co-infect the same host [1], each larva was identified by multiplex PCR to exclude from the analysis individual larvae of either T. spiralis, Trichinella nativa or Trichinella pseudospiralis [15].

\section{Microsatellite analysis}

Total DNA was purified from single larvae as previously described [11]. Single larvae were individually genotyped through the screening of four polymorphic microsatellite loci (Table 2). TS1010B and 
Table 1 Main features of Trichinella britovi isolates used for microsatellite analysis

\begin{tabular}{|c|c|c|c|c|}
\hline No. & ISS code ${ }^{a}$ & Host/source & Locality of origin (region) & Country \\
\hline 1 & 1615 & Domestic pig & Orgosolo (Sardinia) & Italy \\
\hline 2 & 4137 & Red fox & Orgosolo (Sardinia) & Italy \\
\hline 3 & 4138 & Red fox & Orgosolo (Sardinia) & Italy \\
\hline 4 & 3991 & Red fox & Orgosolo (Sardinia) & Italy \\
\hline 5 & 4151 & Red fox & Orgosolo (Sardinia) & Italy \\
\hline 6 & 4152 & Red fox & Orgosolo (Sardinia) & Italy \\
\hline 7 & 4153 & Red fox & Orgosolo (Sardinia) & Italy \\
\hline 8 & 4154 & Red fox & Orgosolo (Sardinia) & Italy \\
\hline 9 & 4155 & Red fox & Orgosolo (Sardinia) & Italy \\
\hline 10 & 4156 & Red fox & Orgosolo (Sardinia) & Italy \\
\hline 11 & 4551 & Domestic pig & Orgosolo (Sardinia) & Italy \\
\hline 12 & 4552 & Red fox & Orgosolo (Sardinia) & Italy \\
\hline 13 & 6226 & Red fox & Orgosolo (Sardinia) & Italy \\
\hline 14 & 1497 & Domestic pig & Cozzano (Corsica) & France \\
\hline 15 & 1572 & Red fox & Cozzano (Corsica) & France \\
\hline 16 & 1573 & Domestic pig & Cozzano (Corsica) & France \\
\hline 17 & 1574 & Domestic pig & Cozzano (Corsica) & France \\
\hline 18 & 1575 & Domestic pig & Cozzano (Corsica) & France \\
\hline 19 & 1576 & Domestic pig & Cozzano (Corsica) & France \\
\hline 20 & 1577 & Domestic pig & Cozzano (Corsica) & France \\
\hline 21 & 1578 & Domestic pig & Cozzano (Corsica) & France \\
\hline 22 & 4126 & Domestic pig & Vallée de Gravona (Corsica) & France \\
\hline 23 & 4127 & Domestic pig & Vallée de Gravona (Corsica) & France \\
\hline 24 & 4130 & Domestic pig & Vallée de Gravona (Corsica) & France \\
\hline 25 & 4131 & Domestic pig & Vallée de Gravona (Corsica) & France \\
\hline 26 & 4132 & Domestic pig & Vallée de Gravona (Corsica) & France \\
\hline 27 & 4244 & Domestic pig & Vallée de Gravona (Corsica) & France \\
\hline 28 & 4245 & Domestic pig & Vallée de Gravona (Corsica) & France \\
\hline 29 & 4669 & Domestic pig & Bastelica (Corsica) & France \\
\hline 30 & $n c^{b}$ & Figatelli ${ }^{c}$ & Aullène (Corsica) & France \\
\hline 31 & $n c^{b}$ & Sausage $^{d}$ & Aullène (Corsica) & France \\
\hline 32 & 6303 & Domestic pig & Aullène (Corsica) & France \\
\hline 33 & 5627 & Wolf & Berceto (Emilia Romagna) & Italy \\
\hline 34 & 5591 & Wolf & Andria (Apulia) & Italy \\
\hline 35 & 6340 & Wild boar & Arquata del Tronto (Marche) & Italy \\
\hline 36 & 5610 & Wolf & Monte S. Angelo (Apulia) & Italy \\
\hline 37 & 5637 & Wolf & Teramo (Abruzzo) & Italy \\
\hline 38 & 6159 & Red fox & Villavallelonga (Abruzzo) & Italy \\
\hline 39 & 6161 & Wolf & Tufara (Molise) & Italy \\
\hline 40 & $\mathrm{nc} c^{\mathrm{b}}$ & Wild boar & Monte S. Angelo (Apulia) & Italy \\
\hline 41 & $\mathrm{nc} c^{\mathrm{b}}$ & Wild boar & Monte S. Angelo (Apulia) & Italy \\
\hline 42 & 244 & Red fox & (Isère) & France \\
\hline 43 & 325 & Red fox & Saint Pierre d'Allevard (Isère) & France \\
\hline 44 & 326 & Red fox & Chichilianne (Isère) & France \\
\hline
\end{tabular}


Table 1 Main features of Trichinella britovi isolates used for microsatellite analysis (Continued)

\begin{tabular}{|c|c|c|c|c|}
\hline No. & ISS code ${ }^{a}$ & Host/source & Locality of origin (region) & Country \\
\hline 45 & 327 & Red fox & Entraigues (Provence) & France \\
\hline 46 & 348 & Red fox & Entemont le vieux (Haute Savoie) & France \\
\hline 47 & 351 & Red fox & Chignin (Haute Savoie) & France \\
\hline 48 & 352 & Red fox & Rimaucourt (Marne) & France \\
\hline 49 & 137 & Red fox & (lozère) & France \\
\hline 50 & 1728 & Wild boar & (Var) & France \\
\hline 51 & 2473 & Wolf & (Var) & France \\
\hline 52 & 2474 & Wild boar & (Ariège) & France \\
\hline 53 & 3992 & Wild boar & (Ariège) & France \\
\hline 54 & 4418 & Wolf & La combe du lars (Haute Savoie) & France \\
\hline 55 & 6302 & Wolf & Péone (Alpes Maritimes) & France \\
\hline 56 & 255 & Wild boar & Jarandilla (Extremadura) & Spain \\
\hline 57 & 5691 & Wild boar & Deleitosa (Extremadura) & Spain \\
\hline 58 & 5694 & Wild boar & Tornavacas (Extremadura) & Spain \\
\hline 59 & 5700 & Wild boar & Fresnedoso de Ibor (Extremadura) & Spain \\
\hline 60 & 5703 & Wild boar & Boltana (Aragon) & Spain \\
\hline 61 & 5710 & Wild boar & Hontanares (Castile and León) & Spain \\
\hline 62 & 5716 & Wild boar & Beraton (Castile and León) & Spain \\
\hline 63 & 5728 & Wild boar & Sabinanigo (Aragon) & Spain \\
\hline
\end{tabular}

a Longitude and latitude values of the locality of isolate origin are available on the website of the International Trichinella Reference Center (https://trichinella.iss.it/ ) using these codes

${ }^{\mathrm{b}} \mathrm{nc}$, no ISS code

'Figatelli originating from domestic pigs of Aullène village marketed in the Nice region (the South of France), where they caused a trichinellosis outbreak [9]

${ }^{\mathrm{d}}$ The sausage was collected from the breeder-butcher, where the figatelli was produced

TS1380 microsatellites were previously described [11], whereas TB922 and TB1019 microsatellites were used here for the first time. PCR conditions for all the four markers are as previously described by La Rosa et al. [12].

Genotyping was accomplished by capillary electrophoresis of PCR products using the Qiaxcel device (Qiagen GmbH, Hilden, Germany) [11]. Alleles were coded by their size in nucleotide base pairs estimated by comparing each peak to reference peaks, whose size had been established by sequencing the amplified homozygote products. If novel alleles were amplified as homozygotes, they were sequenced and included as reference size.

\section{Genetic variability}

Genetic variability per locus, isolate, population and overall loci, was assessed by computing: (i) the mean number of alleles per locus $(\mathrm{Na})$; (ii) effective number of alleles (Ne); (iii) proportion of polymorphic loci (\%Pl); (iv) observed heterozygosity (Ho); and (v) unbiased expected heterozygosity (He) under Hardy-Weinberg expectations (HWE). All values were assessed using Genepop v.4.3 software [16].
The deviation of genotypic frequencies from panmixia was evaluated according to HWE. The accordance to panmixia (as null hypothesis), for each locus per isolate, was evaluated by Fis using the exact test (nominal level $P<0.05$ ) $[17,18]$ by Genepop v.4.3 (settings for Markov chain parameters: dememorization $=1000$, batches $=$ 100 and Markov chain Monte Carlo iterations per batch $=5000)$. The deviation of Ho from He was tested under the hypotheses of heterozygote deficiency or excess for overall loci per isolate (nominal level $P<0.05$ ) by FSTAT v.2.9.3 [19]. Indicative adjusted nominal level to 0.0002 (5040 randomizations), after Bonferroni correction, was also probed by FSTAT v.2.9.3. Since no significant value was detected, these results are not shown. The Bonferroni correction was taken into account testing global HWE for all loci, for overall isolates of each of the five areas. The pairwise differentiation of allele frequencies among isolates and among areas, was tested by Fst and its significance $(P \leq 0.05)$ was computed by Arlequin v.3.5.2.2 [20].

Previous studies on microsatellite analysis of $T$. spiralis isolates have shown that the genetic structure of the isolates are likely unrelated since this parasite showed the capacity to accomplish transmission as highly inbred, admixed lineages and a mixture of both [12]. Consequently, multiple 


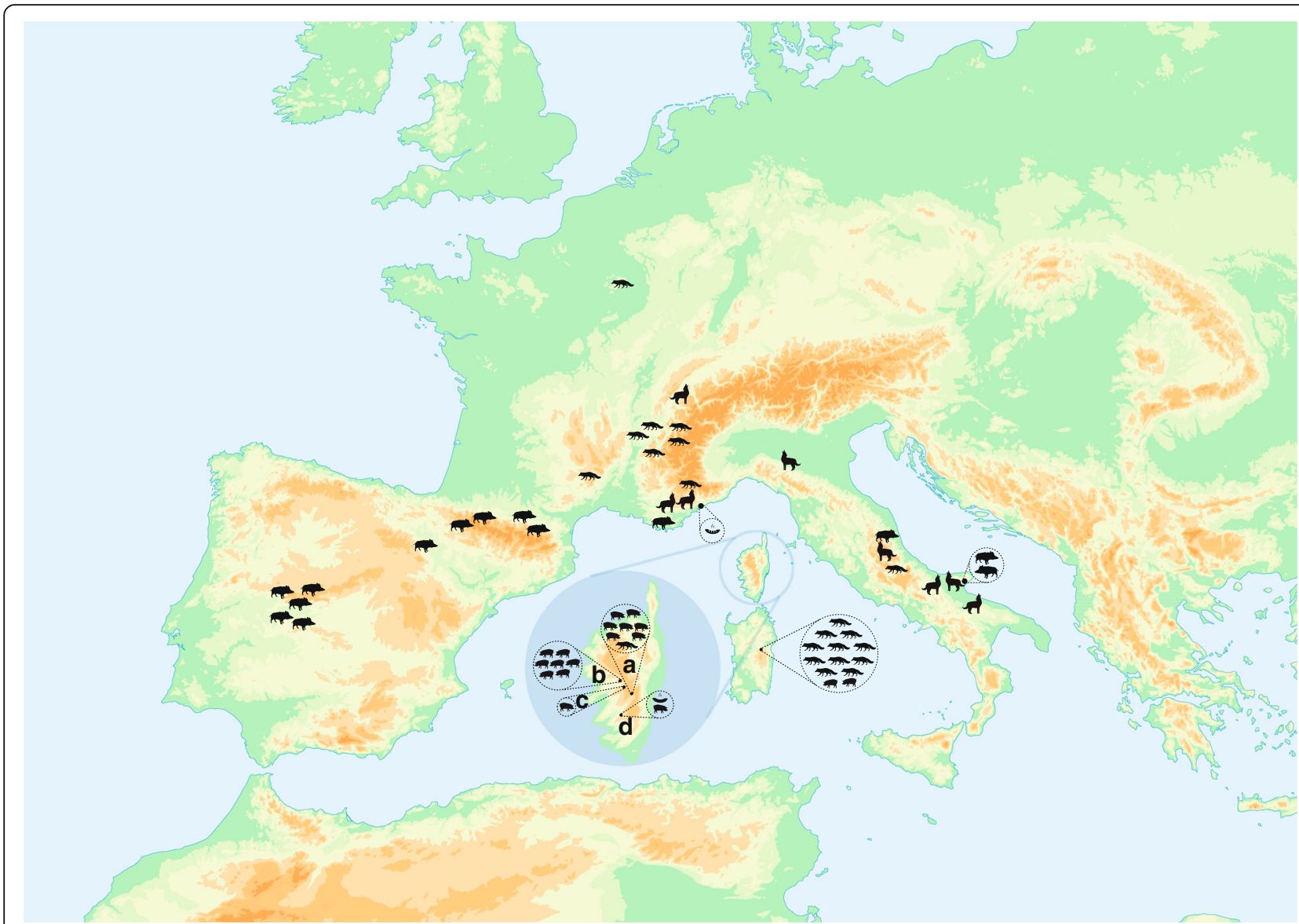

Fig. 1 Geographical and host origin of Trichinella britovi isolates. Isolates investigated by microsatellite analysis originated from the Mediterranean islands of Corsica (Key: a, Cozzano; b, Vallée de Gravona; c, Bastelica; d, Aullène), Sardinia, and from the continent (Italy, France and Spain). Each silhouette shows a T. britovi isolate from domestic pig, wild boar, wolf, fox, or pork sausage

comparisons of the genetic differentiation within each investigated area, were carried out using average values instead of a global analysis.

\section{Genetic structure}

The Bayesian clustering algorithm implemented in STRUCTURE v.2.3.3 [21, 22] was used to infer the genetic structure and relationships among multilocus genotypes (MLGs) of individual larvae. The estimated membership coefficients $(Q)$ were evaluated for each larva and graphically represented by colors. An individual larva is characterized by a vertical bar, where each color represents the proportion of $Q$ that assigns it to the same color inferred $\mathrm{K}$ cluster.

Multiple runs, assuming 1 to 10 subdivisions (K), were performed using a 'burn-in' of 200,000 followed by 100,000 Markov Chain Monte Carlo iterations. Ten simulations were carried out for each $\mathrm{K}$, assuming "admixture" as the ancestry model and "independent frequencies" as allele frequency model. Bayesian analysis was used to perform a detailed evaluation of the genetic structure of the Corsican isolates. Realistic values for $\mathrm{K}$ were evaluated according to Evanno et al. [23] using pophelper webapps [24]. The genetic relationships

Table 2 Trichinella britovi microsatellite primer pairs

\begin{tabular}{|c|c|c|c|}
\hline \multirow[t]{2}{*}{ Code } & \multirow{2}{*}{$\begin{array}{l}\text { Length } \\
\text { (bp) }\end{array}$} & \multicolumn{2}{|l|}{ Primer pairs $\left(5^{\prime}-3^{\prime}\right)$} \\
\hline & & Forward & Reverse \\
\hline TS1010B & 240 & CATTAACGATGTGCTATTTAACGCT & CCAACAACATCCTCAACA \\
\hline TS1380 & 285 & TCAATTCATTTCATTTCAATCTGCG & CACCTTACAATCAAGTAACC \\
\hline TB1019 & 285 & CGGACAGATTCAGCGGA & AGCCAACTCAAGTCCCAAA \\
\hline TB922 & 250 & ATGGGCCAACAACTACCACTA & AAACGGCAATGCAACAAC \\
\hline
\end{tabular}


among isolates were further evaluated by principal coordinates analysis ( $\mathrm{PCoA}$ ), which is unrelated to the Bayesian algorithm, since it does not rely on HWE. PCoA was performed by GenAlEx v.6.2 software [25].

\section{Results}

\section{Genetic variability and differentiation}

An average of 21.7 individual larvae (SE 0.23) from each of the $63 \mathrm{~T}$. britovi isolates from Corsica, Sardinia, and continental Italy, France and Spain, were subjected to PCR amplification using four microsatellite loci. Successful amplification was achieved > 96\% of the time $(\mathrm{TS} 1010 \mathrm{~B}=99.7 \%$; TS1380 $=97.5 \%$; TB1019 = 96.5; and TB922 =91.7\%). No mixed infection with other Trichinella species was detected.

The microsatellite analysis of the 63 isolates revealed appreciable levels of genetic variability as shown by $\mathrm{Na}=$ 2.655 (SE 0.071), $\mathrm{Ne}=1.868(\mathrm{SE} 0.044)$ and $\mathrm{Ho}=0.373$ (SE 0.014) (see Additional file 1: Table S1). All isolates showed at least $50 \%$ of polymorphic loci (Additional file 1 : Table S1). Forty-one isolates were polymorphic at all four loci $(\% \mathrm{Pl}=100), 11$ at three loci $(\% \mathrm{Pl}=75)$, and 11 at two loci $(\% \mathrm{Pl}=50)$ (Additional file 1: Table S1). Fis values of each locus per isolate showed a large variability ranging from negative (-0.429) to positive (0.832) values showing a significant larger (per 18 times) or lower (per 2 times) departure from expectations (nominal level for HWE exact test $P \leq 0.05$ ).

In multiple comparisons, overall the four loci per isolate, the departure (nominal level $P \leq 0.05$ ) of Ho from
He as measured by Fis index, was detected for ten isolates (Nos. 12, 17, 18, 19, 22, 38, 47, 52, 56 and 58) (Additional file 1: Table S1). Nine of them displayed significant larger Fis values than expected, while isolate No. 56 showed a significant lower Fis value. The global test of HWE for all loci and all isolates within the five areas, showed a significant departure of $P$ after Bonferroni adjustment, for all areas excluding Sardinia.

Each geographical area was characterized by different level of genetic variability as suggested by $\mathrm{Na}$ and $\mathrm{Ho}$ values. The Corsican isolates showed the lowest average Ho value $(0.251$, SD 0.084$)$ and the lowest number $(n=$ 13) of alleles. No private allele (i.e. an allele detected in only one studied area) was detected among Corsican isolates. As shown by the Bayesian and PCoA analyses, the Corsican isolates were separated into two clusters, the one of Vallée de Gravona (Nos. 22-28) and the one of Cozzano (Nos. 14-21), which displayed a different genetic variability according to the average Ho values $(0.170$ vs 0.281$)$ and allele number $(n=11$ vs $n=13$, Fig. 2; Additional file 2: Table S2). The Sardinian isolates showed the highest levels of genetic variability (average $\mathrm{Ho}=0.527$, SD 0.061), and the presence of 20 alleles, of which one private (TB1019/277) was detected in all the 13 isolates (Fig. 2, Additional file 2: Table S2).

Trichinella britovi isolates from continental Italy, France, and Spain, showed different levels of genetic variability with average Ho values of 0.409 (SD 0.149; 20 alleles), 0.357 (SD 0.170; 25 alleles), and 0.399 (SD 0.120; 21 alleles), respectively. Trichinella britovi from

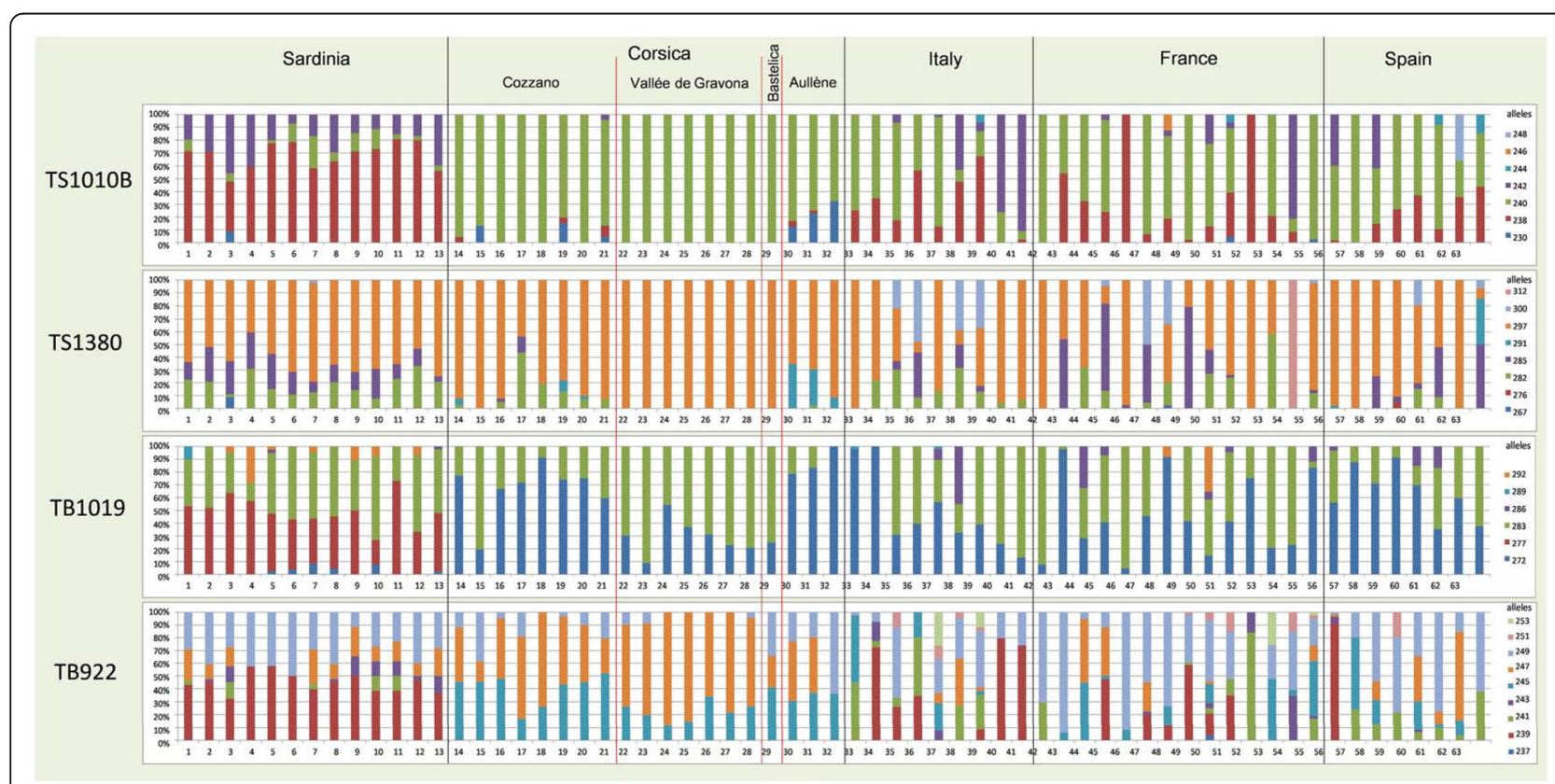

Fig. 2 Allele frequencies of Trichinella britovi larval cohorts. Parasites derived from 63 animals (domestic pigs, wild boars, wolves, red foxes and meat products) of Corsica (four localities) and Sardinia islands, and of continental Italy, France and Spain (see Table 1 for isolate numbers) 
continental France was characterized by three private alleles, TS1010B/246, TB922/237 and TS1380/312, detected in isolate No. 48 (frequency 12\%), No. 50 (frequency 4\%) and No. 54 (frequency 100\%), respectively. Trichinella britovi from continental Spain had two private alleles, TS1380/276 and TS1010B/248, detected in isolate No. 59 (frequency 4\%) and No. 62 (frequency $36 \%$ ), respectively. Trichinella britovi isolates from continental Italy did not show any private allele (Fig. 2, Additional file 2: Table S2). The low genetic variability of $T$. britovi in Corsica was further suggested by the highest number of fixed alleles (29\%), whereas Sardinia and continental Italy, France and Spain showed $0,5,11$ and $9 \%$ of fixed loci, respectively (Additional file 2: Table S2).

The analysis of the genetic differentiation among the 63 isolates (1953 pairwise estimates) evaluated by Fst, showed a significant departure $(P \leq 0.05)$ from the null hypothesis (i.e. all individuals belong to the same population) in $94.9 \%(1854 / 1953)$ of pairwise comparisons (Additional file 3: Table S3).

The analysis of the genetic differentiation within each investigated area, showed high average Fst values ( \pm SD) (Corsica, $0.219 \pm 0.184$; continental Italy 0.348 \pm 0.176 ; continental France $0.432 \pm 0.215$; and continental Spain $0.217 \pm 0.118)$, except for Sardinia $(0.031 \pm 0.048)$ (Table 3$)$.

The analysis of the genetic differentiation among the investigated areas showed high average Fst values for all pairwise comparisons (Table 3). The highest average Fst value $(0.498 \pm 0.077)$ was detected between the two islands, while the lowest average Fst value $(0.281 \pm$ 0.148) was recorded between Corsica and continental Spain (Table 3).

\section{Bayesian analysis of $T$. britovi isolates}

The Bayesian analysis allowed us to assign each larva on the basis of their membership value $(Q)$ to any $K$ cluster superimposed by the algorithm, irrespective of the host from which they were isolated. This analysis was run assuming a range of $\mathrm{K}$, and results were depicted for larvae organized by host origin (Fig. 3). The analysis of the post probability values [23] obtained by different $\mathrm{K}$, did not show clear evidence of separate clusters. Nonetheless, the relationship of the intra-host genetic variability to region-wide genetic variability can be observed in the global analysis of K2-K10 simulations (Fig. 3).

From $K=2$, Corsican and Sardinian isolates were separated into two clusters, whereas the continental isolates from Italy, France and Spain, showed a different genetic ancestry as displayed by color associations (Fig. 3). For example, for $K=5$, isolate No. 46 from continental France was similar to those of Sardinia, recognizable by their blue color, and isolate Nos. 44 and 53 from continental France and No. 62 from continental Spain, recognizable by their magenta color, were genetically similar to those of Vallée de Gravona (Corsica) (Fig. 3). As the $\mathrm{K}$ value increased, the continental isolates showed high levels of intra-isolate complexity (genetic admixture) maintaining kinship relationships with isolates from other continental areas, e.g. isolate No. 40 and No. 41 from continental Italy with isolate No. 54 from continental France and isolate No. 56 from continental Spain, respectively.

The Bayesian analysis of the Corsican isolates (432 larvae) allowed us to understand the kinship affinity and net of interference with the other tested isolates (Fig. 4). Two separate clusters can be distinguished: (i) the isolates (Nos. 14-21) from Cozzano and those (Nos. 3032) from Aullène; and (ii) the isolates (Nos. 22-28) from Vallée de Gravona and that (No. 29) from Bastelica (Fig. 4). The separation of the isolates of Cozzano from those of Vallée de Gravona was already evident for $\mathrm{K}=2$ (Cozzano with a green color pattern versus a red pattern of Vallée de Gravona), and further simulations with higher $\mathrm{K}$ values showed increasing admixture levels, but the separation did not change (Fig. 4).

The MLG of the isolate (No. 29) from Bastelica linked this isolate to those of Vallée de Gravona, independently

Table 3 Average pairwise Fst values (SD) of Trichinella britovi isolates originating from Sardinia, Corsica and continental Italy, France and Spain

\begin{tabular}{|c|c|c|c|c|c|c|c|}
\hline \multirow{2}{*}{$\begin{array}{l}\text { Investigated areas (no. } \\
\text { of tested isolates) }\end{array}$} & \multirow[t]{2}{*}{ Sardinia } & \multicolumn{3}{|l|}{ Corsica } & \multicolumn{3}{|l|}{ Continental } \\
\hline & & All foci & Cozzano & Vallée de Gravona & Italy & France & Spain \\
\hline Sardinia (13) & $0.031(0.048)$ & & & & & & \\
\hline Corsica all foci (19) & $0.498(0.077)$ & $0.219(0.184)$ & & & & & \\
\hline Cozzano (8) & 0.279 & $\mathrm{nd}^{\mathrm{a}}$ & 0.069 & & & & \\
\hline Vallée de Gravona (7) & 0.310 & $n d^{a}$ & 0.122 & 0.036 & & & \\
\hline Continental Italy (9) & $0.342(0.123)$ & $0.389(0.181)$ & 0.219 & 0.277 & $0.348(0.176)$ & & \\
\hline Continental France (14) & $0.396(0.132)$ & $0.415(0.221)$ & 0.230 & 0.297 & $0.391(0.193)$ & $0.432(0.215)$ & \\
\hline Continental Spain (8) & $0.356(0.124)$ & $0.281(0.148)$ & 0.150 & 0.235 & $0.286(0.166)$ & $0.340(0.199)$ & $0.217(0.118)$ \\
\hline
\end{tabular}

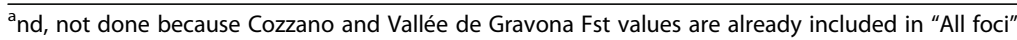




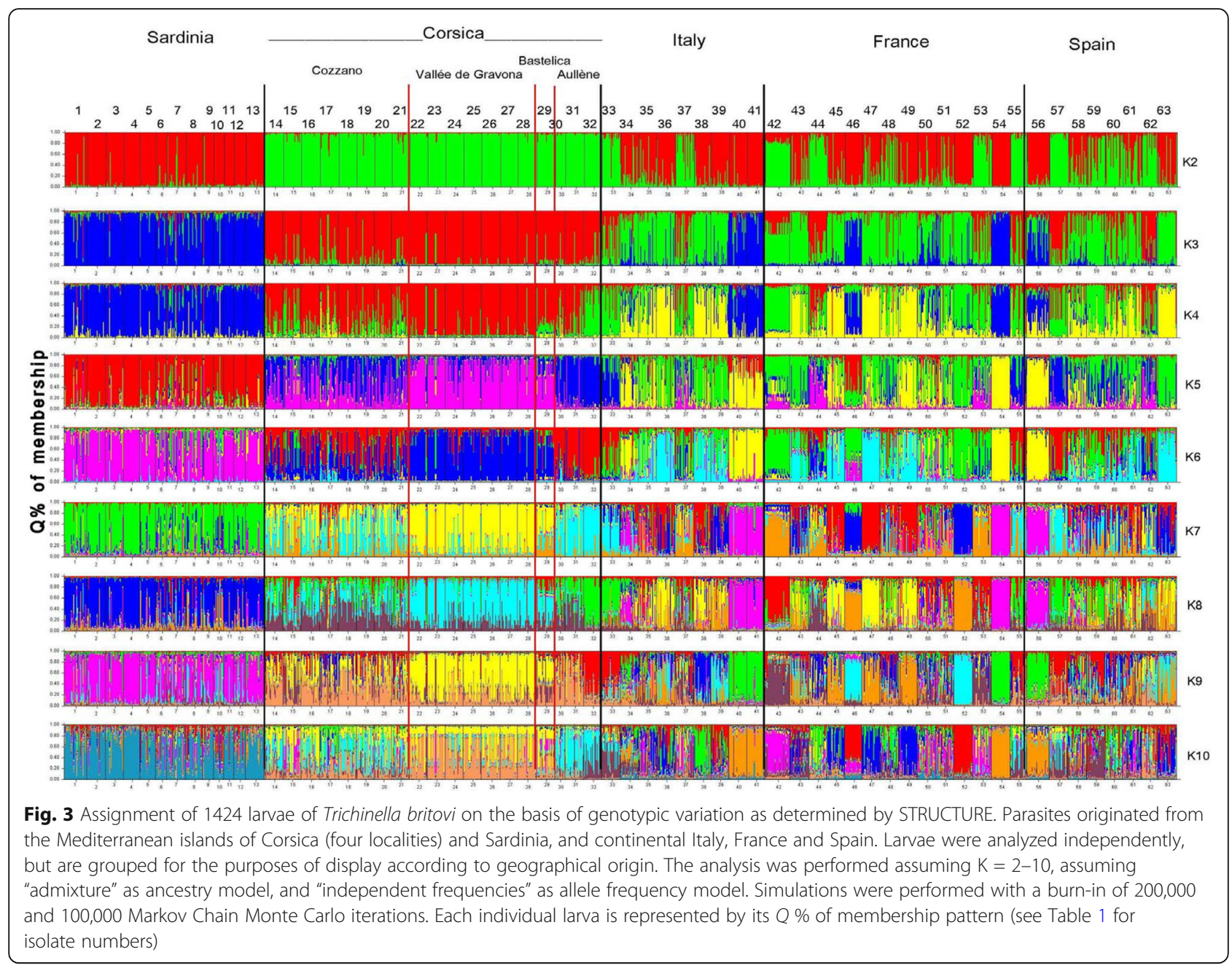

of the $\mathrm{K}$ value, whereas the MLGs of the isolates (Nos. 31-32) of Aullène, while highlighting an admixture level lower than that of the Cozzano isolates, were linked with these isolates for $\mathrm{K}=2$ and $\mathrm{K}=3$ (Fig. 4). The MLG of the isolate No. 30 from "figatelli" marketed in Nice (mainland France), links this isolate to those of Cozzano (Fig. 4). In addition, isolate No. 30 from Nice showed a MLG pattern (for $\mathrm{K}=2-5$ ) very similar (low level of admixture) to that of isolate No. 31, which originated from the sausage collected from the breeder-butcher of Aullène, and to the MLG pattern of isolate No. 32, which originated from a domestic pig of Aullène (Fig. 4).

\section{Multidimensional analysis of $T$. britovi isolates}

The PCoA of the 1424 MLGs identified three main axes, which represent about $60 \%$ of the total variance (Fig. 5). The first two axes (coordinate $1=33 \%$ and coordinate 2 $=17 \%$; Fig. 5a) and the first and third axes (coordinate 1 $=33 \%$ and coordinate $3=10 \%$; Fig. $5 \mathrm{~b}$ ) located the Sardinian isolates along the $\mathrm{x}$-axis opposite to those from Corsica. Furthermore, the Corsican isolates were separated along the $y$-axis in the two clusters of Cozzano and Vallée de Gravona (Fig. 5a). It is noteworthy that the isolates from continental Italy, France and Spain, were distributed in the space between Corsican and Sardinian isolate clusters, without showing specific groupings and superimposing one another randomly (Fig. 5).

\section{Discussion}

The differentiation of the MLG depicted by microsatellite analysis of $T$. britovi isolates originating from Corsica, Sardinia and continental Europe, does not support the assumption of a common recent origin for the parasite populations of the two islands as previously suspected [8], and rewrites the natural history of this zoonotic parasite in the two Mediterranean islands. Most likely, the almost simultaneous appearance of $T$. britovi in Corsica in 2004 and in Sardinia in 2005 was a mere coincidence.

Corsica was considered to be Trichinella-free due to the lack of reports of human or animal infections up until 2004 [7]. At the beginning of the 2000s, there was 

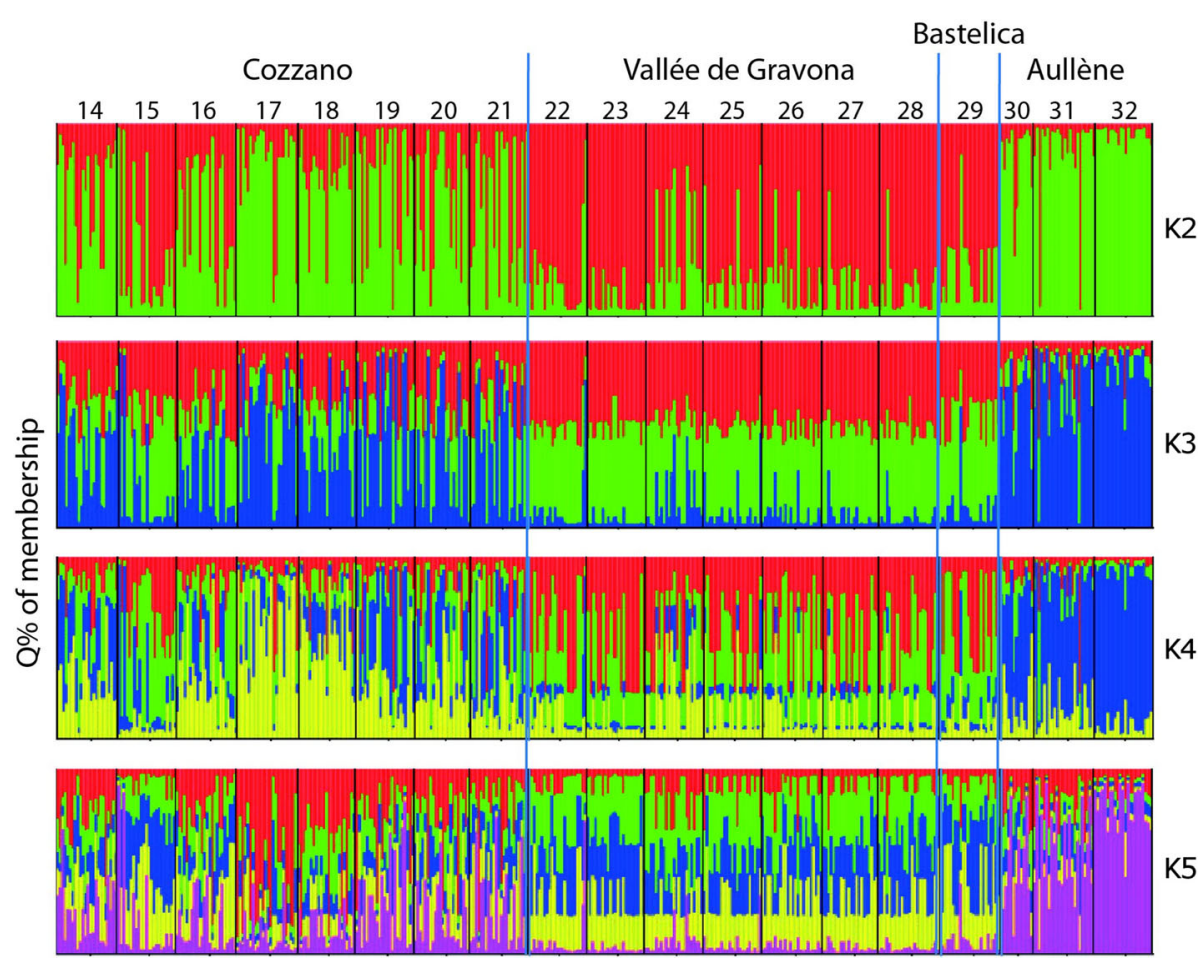

Fig. 4 Bayesian analysis of Trichinella britovi isolates from Corsica (four localities). The numbers (14-32) are those of Table 1. Assignment of 432 larvae of T. britovi on the basis of genotypic variation was determined by STRUCTURE. Larvae were analyzed independently but are grouped for the purposes of display according to the locality of origin. The analysis was performed assuming $K=2-5$, assuming "admixture" as ancestry model, and "independent frequencies" as allele frequency model. Simulations were performed with a burn-in of 200,000 and 100,000 Markov Chain Monte Carlo iterations. Each individual larva is represented by its $Q \%$ of membership pattern

a heightened interest in monitoring Trichinella sp. infections in domestic pigs of the European Union with an improvement in detection methods involving a switch from trichinoscopy to the use of the more sensitive artificial digestion method and analyst training. From 2003 in France, including Corsica, a quality assurance programme was implemented for routine laboratories to monitor Trichinella testing in meat [26].

In Sardinia before the 2005 human outbreak, epidemiological investigations carried out using trichinoscopy, did not detect infection in either domestic or wild animals. Later, however, the analysis of the sample size and sampling localities of the surveys, suggested that methods used could have been inadequate to detect this parasite in the only focus discovered on the island so far [8].

The lack of epidemiological evidence on the circulation of T. britovi in Corsica and Sardinia before its appearance in 2004-2005 is not surprising since epidemiological investigations carried out by serology in Corsica, Italy and in the USA, showed that Trichinella spp. can circulate in a region with a larval burden in host muscles not detectable by direct methods (e.g. artificial digestion) and the presence of the parasite can be only inferred by indirect methods [7, 27-29].
In Ireland, the sylvatic cycle of $T$. spiralis existed for dozens of years independently of whether infection among domestic animals or humans had been demonstrated [30].

The wide variability of the genetic structure observed in the continental T. britovi isolates (Fig. 3) is probably related to the wide extension of the geographical area of sampling (Fig. 1) and to the limited host migration and genetic exchanges among isolates as observed in T. spiralis of the Extremadura region of Spain [12].

The $Q$ membership values of $T$. britovi isolates of Corsica and Sardinia showed a substantial intra-isolate MLG homogeneity and they appear differentiated from one another irrespective of the $\mathrm{K}$ value (Fig. 3) and from continental T. britovi isolates, where a higher level of admixture occurs. However, with increasing $\mathrm{K}$ values, several larvae from the two islands showed admixture with larvae of continental areas (e.g. $\mathrm{K}=5$, Sardinia $v s$ France No. 46; Corsica vs France No. 44 and Spain No. 57) (Fig. 3).

The multidimensional analysis supports that Corsica and Sardinia harbor genetically differentiate isolates over all the three main axes (Fig. 5), while the continental isolates are overdispersed in the three-dimensional space (Fig. 5), as it is likely that the large distances among 

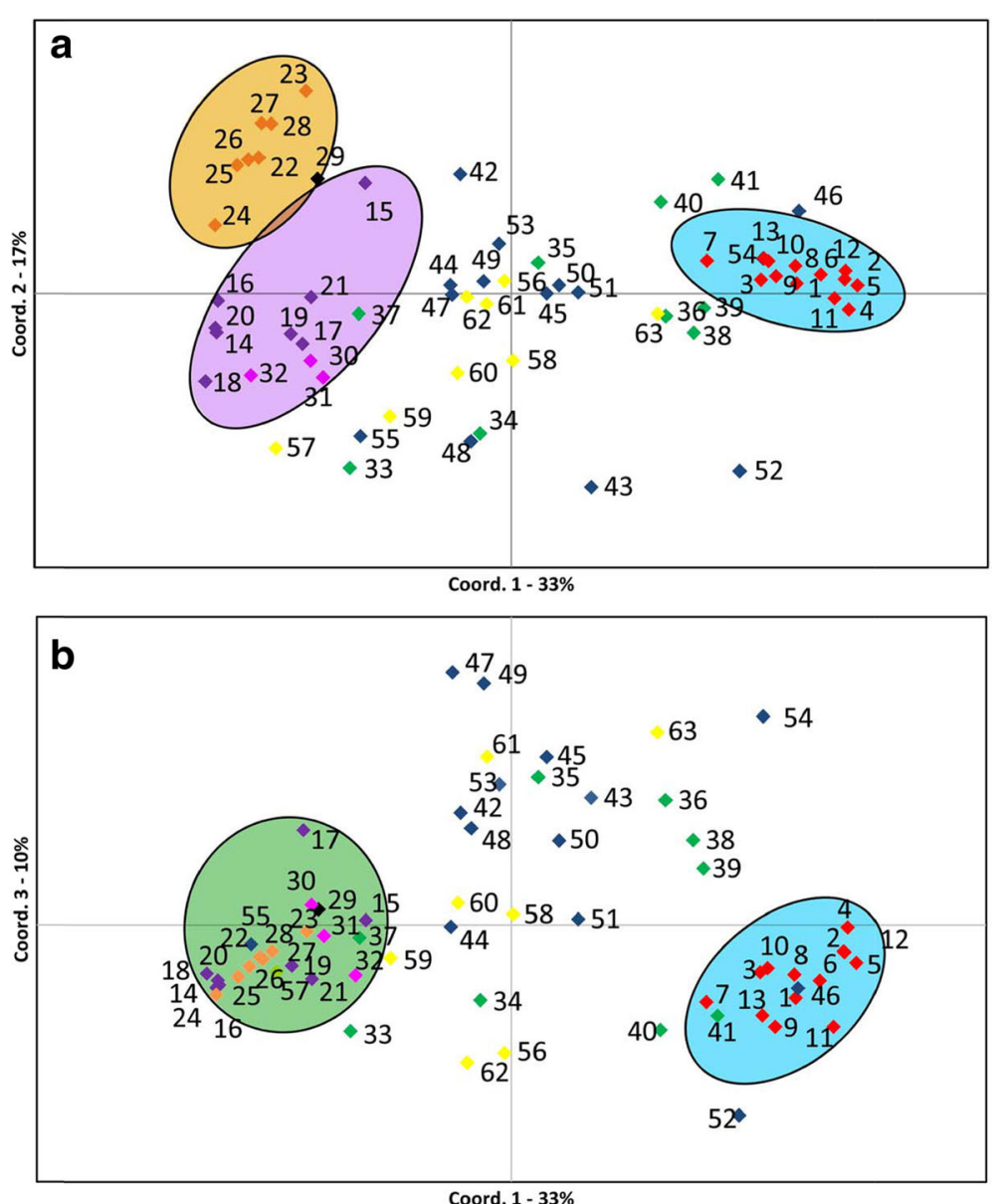

Fig. 5 Principal component analysis of Trichinella britovi larval cohorts. Parasites derived from 63 animals (domestic pigs, wild boar, wolves, red foxes and meat products). a Coordinate 1 vs coordinate 2. Circles are drawn arbitrarily, but emphasize groupings of isolates of Corsica (Vallée de Gravona, yellow circle; Cozzano, violet circle) and Sardinia (blue circle), and of continental Europe (Italy, France and Spain). b Coordinate 1 vs coordinate 3. Circles are drawn arbitrarily, but emphasize groupings of isolates of Corsica (green circle) and Sardinia (blue circle), and of continental Europe (Italy, France and Spain) (see Table 1 for isolate numbers)

sampled continental isolates are a factor limiting the gene flow.

Both Bayesian and PCoA independent algorithms show two T. britovi clusters segregated in remote valleys of Corsica (Figs. 4 and 5a), suggesting a low genetic exchange among them due to the island orography and likely human behavior.

According to Bayesian and PCoA analyses, the Corsican isolates are separated into two clusters related to Cozzano and Vallée de Gravona. On the basis of presence/absence of alleles, the seven isolates of Vallée de Gravona are fixed to one of the four alleles identified in the Cozzano valley (TS1010B/240; TS1380/297) (Fig. 2, Additional file 2: Table S2). Alleles detected in the Bastelica isolate are fixed for the same alleles (TS1010B/240, TS1380/297) as observed in Vallée de Gravona (Fig. 2, Additional file 2: Table S2). Alleles detected in the three Aullène isolates resemble those detected in Cozzano
(Fig. 2, Additional file 2: Table S2). The genetic structure observed by the Bayesian analysis confirms the associations between Bastelica and Vallée de Gravona isolates, as well as between Aullène and Cozzano isolates, since they are assigned to the same clusters for all $\mathrm{K}$ values (Fig. 4). The homogeneity of the $Q$ membership of individuals suggests that genetic drift affected the allele frequencies of the loci of the Aullène isolates. The MLG analysis of the 31 continental T. britovi isolates appears to be inadequate to identify the European region of origin of the T. britovi populations detected in the two Mediterranean islands. The sharing of one or more alleles between two geographical populations only, could suggest that one population derives from the other. Based on the presence/absence of alleles in T. britovi populations of Corsica and Sardinia, we observed that Corsica shares one allele (TS1380/291) with continental Spain, whereas Sardinia shares two alleles (TS1380/267, 
TB1019/292) with continental France and one allele (TB1019/289) with continental Italy (Additional file 2: Table S2). We can speculate that T. britovi populations of the two islands did not derive from each other at least in recent times. Furthermore, the allele sharing suggests that the Corsica population could originate from Spain and the Sardinia population could originate from France/Italy. The two island populations could have separately evolved as unique genetic structures different to those typical of $T$. britovi continental populations.

The MLG analysis of T. britovi larvae isolated from figatelli (isolate No. 30) marketed in the Nice region (the South of France), where they caused a human outbreak, links their origin with larvae isolated from a sausage (isolate No. 31) collected at the breeder-butcher of Aullène and with larvae from a domestic pig (isolate No. 32) reared in Aullène (Corsica) (Fig. 4). This result supports the epidemiological investigation carried out following the outbreak [9]. In addition, the MLG analysis suggests that larvae isolated from pork delicatessen produced in Aullène and those from the domestic pig of Aullène originated from the Cozzano focus. It follows that the MLG analysis could be a powerful tool to trace "from fork to farm" the origin of $T$. britovi infections and the trade of infected animals and/or food.

The red fox is one of the most important natural reservoir hosts of T. britovi in Europe [31]. Today, the Corsican and Sardinian foxes are recognized as a subspecies (Vulpes vulpes ichnusae) of the continental population. This canid colonized these Mediterranean islands during the Middle Pleistocene and Early Holocene (from 700 to 11,000 B.C.) when a terrestrial bridge allowed the migration of mammals from continental Italy to the two islands [32]. Since T. britovi probably diversified from an ancestral species in the Pleistocene [33, 34], we can speculate that foxes, which colonized the two islands, were infected by this parasite. In Corsica and Sardinia, hunters do not collect fox carcasses after hunting, thus favoring the transmission of $T$. britovi to wild boar and domestic pigs as extensive breeding is a common practice on both islands.

Other carnivores present in Corsica and Sardinia such as the wild cat (Felis lybica sarda), probably introduced by Phoenicians between the 9th and 3rd century B.C. [35], the marten (Martes martes) and the weasel (Mustela nivalis), do not play an important role as reservoir hosts, and T. britovi has been not detected in these species of the two islands so far.

The wild boar of Corsica and Sardinia has been described as a subspecies (Sus scrofa meridionalis), which was not present on these islands before the 7000 B.C. and may have originated from domestic pigs introduced by humans, an origin from independently domesticated swine on the Italian mainland that have since gone feral [36]. Even though domestic and wild pigs cannot be considered as good reservoir hosts for $T$. britovi $[1,31]$, they could have introduced $T$. britovi in Corsica and Sardinia in ancient times.

At the end of the 1970s, the near disappearance of the wild boar population in Corsica due to classical swine fever was followed by the introduction of wild boar from the Ardennes, mainland France [37]. Today, Corsica has the highest density of wild boar and free ranging pig populations of France [38].

Finally, hunting dogs can also be considered as a possible source of infection for domestic and wild swine, since T. britovi larvae and/or anti-Trichinella antibodies have been detected in these animals [29]. In Corsica, epidemiological evidence suggests that when a hunting dog dies during hunting, its carcass is usually used to feed domestic pigs (Vallée I., unpublished data).

\section{Conclusions}

This microsatellite analysis suggests that T. britovi was introduced to the two Mediterranean islands of Sardinia and Corsica by two or more independent events and that gene flow among the T. britovi isolates of Corsica is very limited and restricted to small foci present in the deep valleys. Furthermore, the MLG analysis proved to be a useful tool to trace "from fork to farm" the T. britovi infection source. The MLG analysis may be a suitable method to describe the natural history of insular populations of T. britovi, supporting epidemiological investigations during outbreaks, whereas its use at the continental level could be more difficult due to the limited amount of data. Therefore, the screening of a larger number of T. britovi isolates using the MLG analysis will be necessary to provide a useful tool for epidemiological investigations within continental areas.

\section{Additional files}

Additional file 1: Table S1. Genetic variability of 63 Trichinella britovi isolates from two Mediterranean islands and three continental regions. (PDF 89 kb)

Additional file 2: Table S2. Allele frequencies and sample size of Trichinella britovi larval cohorts derived from 63 animals. (PDF 53 kb)

Additional file 3: Table S3. Pairwise Fst values of the 63 Trichinella britovi isolates. (PDF $240 \mathrm{~kb}$ )

\section{Abbreviations \\ \%Pl: Proportion of polymorphic loci; He: Unbiased expected heterozygosity; Ho: Observed heterozygosity; HWE: Hardy-Weinberg expectations; MLG: Multilocus genotype; Na: Mean number of alleles per locus; Ne: Effective number of alleles; PCoA: Principal coordinates analysis; Q: Estimated membership coefficients}

Funding

This study was in part supported by the DG SANTE of the European Commission (grants 2013-2016). 


\section{Availability of data and materials}

The data supporting the conclusions of this article are included within the article and its additional files. Raw data presented are available at the Istituto Superiore di Sanità (Dr. Giuseppe La Rosa, email: giuseppe.larosa@iss.it).

\section{Authors' contributions}

All the authors have contributed significantly to this study. GL designed the study, performed data analysis and contributed to writing the article. IV collected samples and performed epidemiological investigations in Corsica and mainland France. GM performed the molecular study of microsatellites and reporting. FC and EB collected the samples and performed the epidemiological investigations in Corsica and Sardinia, respectively. FG developed the database of Trichinella isolates. PB participated in the investigation and contributed to the manuscript. EP contributed to designing the study and to writing the article. All authors read and approved the final manuscript.

\section{Ethics approval and consent to participate}

Not applicable.

\section{Consent for publication}

Not applicable.

\section{Competing interests}

The authors declare that they have no competing interests.

\section{Publisher's Note}

Springer Nature remains neutral with regard to jurisdictional claims in published maps and institutional affiliations.

\section{Author details}

${ }^{1}$ European Union Reference Laboratory for Parasites, Istituto Superiore di Sanità, Rome, Italy. ${ }^{2}$ Animal Health Laboratory, OIE Collaborating Centre for Foodborne Zoonotic Parasites, JRU BIPAR, Anses, ENVA, INRA, Université Paris Est, Maisons-Alfort, France. ${ }^{3}$ INRA, Corte, France. ${ }^{4}$ Istituto Zooprofilattico Sperimentale della Sardegna, Nuoro, Italy.

Received: 16 March 2018 Accepted: 6 June 2018

Published online: 19 June 2018

\section{References}

1. Pozio E, Zarlenga DS. New pieces of the Trichinella puzzle. Int J Parasitol. 2013:43:983-97.

2. Pozio E. Searching for Trichinella: not all pigs are created equal. Trends Parasitol. 2014:30:4-11.

3. Pozio E, La Rosa G. Identification of the likely etiologic agent of human trichinellosis in Sicily (Italy) between 1933 and 1946. Am J Trop Med Hyg. 1998:59:906-7.

4. EFSA. Feasibility of establishing Trichinella-free areas, and it feasibility on the risk increase to public health of not examining pigs from those areas for Trichinella spp. EFSA J. 2005;277:1-37.

5. Pozio E, Mesina P, Sechi F, Pira M, Liciardi M, Cossu P, et al. Human outbreak of trichinellosis in the Mediterranean island of Sardinia, Italy. Vet Parasitol. 2006;140:177-80.

6. Pozio E, Cossu P, Marucci G, Amati M, Ludovisi A, Gomez Morales MA, et al. The birth of a Trichinella britovi focus on the Mediterranean island of Sardinia (Italy). Vet Parasitol. 2009;159:361-3.

7. Richomme C, Lacour SA, Ducrot C, Gilot-Fromont E, Casabianca F, Maestrini $\mathrm{O}$, et al. Epidemiological survey of trichinellosis in wild boar (Sus scrofa) and fox (Vulpes vulpes) in a French insular region, Corsica. Vet Parasitol. 2010;172:150-4

8. Bandino E, Goddi L, Mulas M, Murgia MC, Soddu M, Marucci G, et al. Trichinella britovi from domestic to wild animals of Sardinia, Italy. Vet Parasitol. 2015;212:262-6.

9. Ruetsch C, Delaunay P, Armengaud A, Peloux-Petiot F, Dupouy-Camet J, Vallée I, et al. Inadequate labeling of pork sausages prepared in Corsica causing a trichinellosis outbreak in France. Parasite. 2016;23:27.

10. Rosenthal BM, La Rosa G, Zarlenga D, Dunams D, Chunyu Y, Mingyuan L, et al. Human dispersal of Trichinella spiralis in domesticated pigs. Infect Genet Evol. 2008;8:799-805.
11. La Rosa G, Marucci G, Rosenthal BM, Pozio E. Development of a single larva microsatellite analysis to investigate the population structure of Trichinella spiralis. Infect Genet Evol. 2012;12:369-76.

12. La Rosa G, Calero-Bernal R, Pérez-Martín JE, Tonanzi D, Galati F, SerranoAguilera FJ, et al. Rare but evolutionarily consequential outcrossing in a highly inbred zoonotic parasite. Int J Parasitol. 2018;48:543-53.

13. European Commission. Regulation (EC) No 2075/2005 of 5 December 2005 laying down specific rules on official controls for Trichinella in meat. Off J Eur Union. 2005;L338:60-82.

14. European Commission. Commission implementing regulation (EU) 2015/ 1375 of 10 August 2015 laying down specific rules on official controls for Trichinella in meat. Off J Eur Union. 2015;L212:7-34.

15. Pozio E, La Rosa G. Trichinella. In: Liu D, editor. Molecular detection of foodborne pathogens. Boca Raton: CRC Press; 2010. p. 851-63.

16. Rousset F. Genepop'007: a complete re-implementation of the genepop software for Windows and Linux. Mol Ecol Resour. 2008;8:103-6.

17. Haldane JBS. An exact test for randomness of mating. J Genetics. 1954; 52:631-5

18. Weir BS. Genetic Data Analysis II. Sunderland: Sinauer; 1996.

19. Goudet J. FSTAT (version 1.2): a computer program to calculate F-Statistics. J Hered. 1995:86:485-6.

20. Excoffier L, Laval G, Schneider S. Arlequin version 3.0: An integrated software package for population genetics data analysis. Evol Bioinform Online. 2005;1:47-50.

21. Pritchard JK, Stephens M, Donnelly P. Inference of population structure using multilocus genotype data. Genetics. 2000;155:945-59.

22. Falush D, Stephens M, Pritchard J. Inference of population structure using multilocus genotype data: linked loci and correlated allele frequencies. Genetics. 2003:164:1567-87.

23. Evanno G, Regnaut S, Goudet J. Detecting the number of clusters of individuals using the software STRUCTURE: a simulation study. Mol Ecol. 2005:14:2611-20.

24. Francis RM. Pophelper: an R package and web app to analyse and visualize population structure. Mol Ecol Resour. 2017:17:27-32.

25. Peakall R, Smouse P. GenAlEx 6: genetic analysis in Excel. Population genetic software for teaching and research. Mol Ecol Notes. 2006:6:288-95.

26. Vallée I, Macé P, Forbes L, Scandrett B, Durand B, Gajadhar A, et al. The use of proficiency samples to assess diagnostic laboratories in France performing a Trichinella digestion assay. J Food Prot. 2007;70:1685-90.

27. Gómez Morales MA, Ludovisi A, Amati M, Bandino E, Capelli G, Corrias F, et al. Indirect versus direct detection methods of Trichinella spp. infection in wild boar (Sus scrofa). Parasit Vectors. 2014;7:171.

28. Hill DE, Dubey JP, Baroch JA, Swafford SR, Fournet VF, Hawkins-Cooper D, et al. Surveillance of feral swine for Trichinella spp. and Toxoplasma gondii in the USA and host-related factors associated with infection. Vet Parasitol. 2014;205:653-65.

29. Gómez-Morales MA, Selmi M, Ludovisi A, Amati M, Fiorentino E, Breviglieri L, et al. Hunting dogs as sentinel animals for monitoring infections with Trichinella spp. in wildlife. Parasit Vectors. 2016;9:154.

30. Rafter P, Marucci G, Brangan P, Pozio E. Rediscovery of Trichinella spiralis in red foxes (Vulpes vulpes) in Ireland after 30 years of oblivion. J Infect. 2005; 50:61-5.

31. Pozio E, Rinaldi L, Marucci G, Musella V, Galati F, Cringoli G, et al. Hosts and habitats of Trichinella spiralis and Trichinella britovi in Europe. Int J Parasitol. 2009:39:71-9.

32. Frati F, Hartl GB, Lovari S, Delibes M, Markov G. Quaternary radiation and genetic structure of the red fox Vulpes vulpes in the Mediterranean Basin, as revealed by allozymes and mithocondrial DNA. J Zool Lond. 1998;245:43-51.

33. Zarlenga DS, Rosenthal BM, La Rosa G, Pozio E, Hoberg EP. Post-Miocene expansion, colonization, and host switching drove speciation among extant nematodes of the archaic genus Trichinella. Proc Natl Acad Sci USA. 2006; 103:7354-9.

34. Korhonen PK, Pozio E, La Rosa G, Chang BC, Koehler AV, Hoberg EP, et al. Phylogenomic and biogeographic reconstruction of the Trichinella complex. Nat Commun. 2016;7:10513.

35. Mattucci F, Oliveira R, Bizzarri L, Vercillo F, Anile S, Ragni B, et al. Genetic structure of wildcat (Felis silvestris) populations in Italy. Ecol Evol. 2013;3: 2443-58.

36. Larson G, Dobney K, Albarella U, Fang M, Matisoo-Smith E, Robins J, et al. Worldwide phylogeography of wild boar reveals multiple centers of pig domestication. Science. 2005;307:1618-21. 
37. Richomme C. Epidémiologie de zoonoses du sanglier (Sus scrofa) dans un milieu méditerranéen insulaire, la Corse. Biologie animale. Université Blaise Pascal - Clermont-Ferrand II, 2009. Français. https://tel.archives-ouvertes.fr/ tel-00724959/document.

38. Anonymous. Le sanglier. 2013. http://www.oncfs.gouv.fr/Connaitre-lesespeces-ru73/Le-Sanglier-ar994. Accessed 9 March 2018.

Ready to submit your research? Choose BMC and benefit from:

- fast, convenient online submission

- thorough peer review by experienced researchers in your field

- rapid publication on acceptance

- support for research data, including large and complex data types

- gold Open Access which fosters wider collaboration and increased citations

- maximum visibility for your research: over $100 \mathrm{M}$ website views per year 